khối u [4]. Tỷ lệ tái phát tại chổ cho các phương pháp phẫu thuật trong u là $27 \%$, tỷ lệ tái sau cắt toàn bộ biên được báo cáo sắp xỉ $8 \%$ [7]. Tỷ lệ tái phát giảm hoàn toàn khi cắt bỏ toàn bộ khối u. Tỷ lệ tái phát dường như liên quan trực tiếp với sự lan rộng của u. Tuy nhiên, việc cắt rộng tại chổ của khối u nói chung bất tiện các u ở sàn sọ và xương thái dương do liên quan với các cấu trúc sinh tồn và biến chứng. Vai trò của xạ trị hổ trợ trong điều trị vẫn còn tranh luận. Xa trị được khuyến cáo cho khối u mà khối u đó chưa được cắt bỏ hoàn toàn. Một số quan điểm xạ trị có thể kích thích chuyển qua sarcom của u đại bào. Hóa trị và xạ trị không đóng vai trò chính trong điều trị u đại bào [6].

3.6. Tiên lượng: $U$ đại bào của sàn sọ có tỷ lệ tái phát $40-60 \%$ [6]. U đại bào là các khối u lành tính lớn và di căn trong $5-10 \%$ trường hợp, phổ biến nhất là di căn phổi [4].

\section{KẾT LUÂN}

Chẩn đoán và điều trị u đại bào của sàn sọ là một thách thức với các phẫu thuật viên Tai Mũi Họng. Chẩn đoán xác định dựa vào giải phẫu bểnh. $U$ đại bào là u lành tính nhưng có khả nắng hóa ác. Phẫu thuật hiện này vẫn là phương pháp tốt nhất trong chọn lựa điều trị.

\section{TÀI LIÊU THAM KHẢO}

1. Akyigit A, Karlidag T, Sakallioglu Ö, Polat $C_{r}$ Keles E. Giant cell tumor of bone involving the temporomandibular joint and temporal bone. J Craniofac Surg 2014; 25: 1397-9.

2. Freeman JL, Oushy S, Schowinsky J, Sillau S, Youssef AS. Invasive giant cell tumor of the lateral skull base: a systematic review, metaanalysis, and case illustration. World Neurosurg 2016; 96: 47-57.

3. Lee JA, et al. Giant cell tumor of the skull. Radiographics 1998;18(5):1295-302.

4. Iizuka $\mathbf{T}$, et al. Giant cell tumor of the temporal bone with direct invasion into the middle ear and skull base: a case report. Case Reports in Otolaryngology 2012;2012:4.

5. Leonard J, et al. Malignant giant-cell tumor of the parietal bone: case report and review of the literature. Neurosurgery 2001;48(2):424-9.

6. Tamura $\mathbf{R}$, et al. Giant cell tumor of the skull: review of the literature. J Neurol Surg Cent Eur Neurosurg 2016;77(3):239-46.

7. Matsushige T, Nakaoka M, Yahara K, Kagawa K, Miura H, Ohnuma $H$, et al. Giant cell tumor of the temporal bone with intratumoral hemorrhage. J Clin Neurosci 2008; 15: 923-7.

8. Murphey MD, et al. From the archives of AFIP. Imaging of giant cell tumor and giant cell reparative granuloma of bone: radiologicpathologic correlation. Radiographics 2001;21(5):1283-309.

\title{
HIỆU QUẢ DỰ PHÒNG VÀ ĐIỀU TRI SÂU RĂNG BẰNG VÉC-NI FLUOR (5\%) VÀ KEM ĐÁNH RĂNG CÓ FLUOR TRÊN TRẺ EM 7-8 TUỔI
}

\section{Nguyễn Mạnh Cường ${ }^{1,2}$, Lê Thị Thu Hà ${ }^{1,3}$, Đào Thị Dung}

\section{TÓM TẮT}

Vai trò của fluor nói chung, véc-ni fluor nói riêng trong dự phòng và điều trị bệnh sâu răng ngày càng được hiểu rõ. Nhiều nghiên cứu đã khẳng định những đóng góp của fluor trong việc làm hạ thấp tỷ lệ và mức độ trâm trọng của sâu răng trên toàn cầu. Nghiên cứu được tiển hành trên 258 trẻ em 7-8 tuổi với mục tiêu: Đánh giá hiệu quả dự phòng sâu răng bằng véc-ni fluor $5 \%$ và kem đánh răng có fluor. Đây là nghiên cứu can thiêp lâm sàng có đối chứng được tiến hành sau một nghiên cứu mô tả cắt ngang trển 1212 học sinh tại 6 Quận, Huyện tại thành phố Hà

\footnotetext{
${ }^{1}$ Viện nghiên cứu Khoa học Y Dược Lâm sàng 108

${ }^{2}$ Trường Đại học Kỹ thuật $Y$ - Dược Đà Nẵng

${ }^{3}$ Bệnh viện Trung ương Quân đội 108

${ }^{4}$ Trường Đại học Y Dược - Đại học Quốc gia Hà Nội.

Chịu trách nhiệm chính: Nguyễn Mạnh Cường

Email: dr.manhcuong@gmail.com

Ngày nhận bài: 17.5.2021

Ngày phản biên khoa họ: 6.7.2021

Ngày duyệt bài: 19.7.2021
}

Nôi. Các cháu được chon vào khám, đánh giá tình trạng bệnh sâu răng, sau đó được chia thành 2 nhóm: nhóm 1 gồm những bôi véc-ni fluor, nhóm 2 được chải kem đánh răng có fluor. Sau mỗi 6 tháng, 12 tháng và 24 tháng các cháu đước tái khám để đánh giá tình trang bệnh sâu răng. Kểt quả cho thấy, nhóm sử dụng véc-ni fluor có tỷ lệ sâu răng thấp hơn nhóm sử dụng kem đánh răng có fluor. Từ kết quả này có thể đưa ra khuyến cáo: véc-ni fluor là một trong các lựa chọn tốt để dự phòng bệnh sâu răng cho trẻ em tại cộng đồng.

Tư khóa: sâu răng, véc-ni fluor, trẻ em.

\section{SUMMARY \\ EFFICACY OF TOPICAL FLUORIDE VARNISH AND FLUORIDE TOOTHPASTE IN DENTAL CARIES PREVENTION IN CHILDREN}

The roles of fluoride in general and fluoride varnish in particular in the prevention and treatment of dental caries is increasingly understood. Many studies have confirmed the contributions of fluoride in reducing the prevalence and the severity of dental caries all over the world. The study was conducted on 258 children who is 7 years old with the objectives: To evaluate the caries prevention effects of $5 \%$ fluoride varnish and 
fluoride toothpaste. This is a randomized controlled clinical study conducted after a descriptive crosssectional study on 1212 students in 6 districts in Hanoi city. The children were selected to be examined and evaluated for their caries status, then divided into two groups: in the first group, children were applied with $5 \%$ fluoride varnish, in the second group children were asked to use fluoride toothpaste for daily brushing. After every 6 months, 12 months and 24 months the children were re-examined to evaluate their dental caries status. The study results showed that the group using fluoride varnish had a lower prevalence of dental caries than the group using fluoride toothpaste. From these results, it is possible to make recommendations: The use of fluoride varnish is one of the good choices to prevent dental caries for children in the community.

Key word: dental caries, fluoride varnish, children.

\section{I. ĐĂT VẤN ĐỀ}

Việc không phát hiện ra hoạt động sâu răng sớm có thể khiến bác sĩ không có lựa chọn nào khác ngoài điều trị phục hồi, thay vì áp dụng các biện pháp không xâm lấn. Việc tìm ra được nguyên nhân, cơ chế bệnh sinh của bệnh sẩu răng đã dẫn tới sự thay đổi trong dự phòng và điều trị sâu răng, quan điểm ngày nay không chỉ dừng lại ở mức khoan trám lại các tổn thương sâu răng đã tạo thành lỗ sâu mà còn bao gồm phòng và điều trị các tổn thương sâu răng sớm (chưa tạo lố sâu) nhằm giảm chi phí và tăng hiệu quả điều trị [6].

Với hơn 50 năm nghiên cứu trên thực nghiệm và lâm sàng fluor đóng vai trò là tác nhân tiêu chuẩn vàng trong dự phòng và điều trị sâu răng [5], làm hạ thấp tỷ lệ và mức độ trầm trọng của sâu răng trên toàn cầu, nghiên cứu của Marinho VC và cộng sự, qua phân tích tổng hợp các nghiên cứu can thiệp bằng véc-ni fluor thấy vécni fluor làm giảm sẩu răng là 33\% $(95 \%$ CI, $19 \%$ - 46\%) [1], [4]. Thêm vào đó là sự phát triển nhanh chóng của công nghiệp hóa chất cho ra đời các sản phẩm chứa fluor ngày càng đa dạng về chủng loại và chất lượng cũng như cách sử dụng [3]. Trền thế giới các nghiên cứu về véc -ni fluor đã tập trung làm rõ cơ chế tác dụng, hiệu quả phòng và điêu trị sâu răng, liều lượng và cách dùng... của các dạng véc-ni fluor khác nhau. Tuy nhiên những nghiên cứu này vẫn còn nhiều hạn chế như chưa đưa ra được một phương pháp hoàn hảo (hiệu quả cao, an toàn, đơn giản khi sử dụng), chưa tìm ra liều lượng tối ưu cho các giai đoạn của tổn thương sâu răng [2].

Tại Việt Nam đến nay mặc dù có rất nhiều công trình nghiên cứu về sâu răng [7] ở tất cả các lứa tuổi song đa số những nghiên cứu này mới chỉ dừng lại ở việc chẩn đoán được sâu răng ở các giai đoạn muộn, vì vậy việc phòng và điều trị bệnh cho hiệu quả còn thấp. Chưa có nghiên cứu nào về tình trạng sâu răng của trẻ em trong việc sử dụng véc-ni fluor để can thiệp dự phòng và điêu trị sâu răng.

Xuất phát từ các vấn đề trên chúng tôi tiên hành thực hiện đề tài "Nghiên cứu sư dưng vécni fluor trong dự phòng và điều trị sâu răng".

\section{II. ĐỐI TƯỢNG VÀ PHƯƠNG PHÁP NGHIÊN CỨU}

2.1 Dân số mục tiêu: + Từ kết quả của nghiên cứu cắt ngang mô tả 1212 học sinh trên địa bàn Hà Nội, chúng tôi đã chọn ngấu nhiên các học sinh , lên danh sách các học sinh có ít nhất 1 răng sấu vĩnh viễn.

\subsection{Dân số nghiên cứu (Tiêu chuẩn lựa} chọn): + Có $\geq 1$ răng vĩnh viễn sâu.

+ Đồng ý và tự nguyện tham gia nghiên cứu (có phiếu chấp thuận và đồng ý của phụ huynh hoặc người giám hộ).

- Tiêu chuẩn loại trừ: + Học sinh chưa có răng hàm lớn số 6 mọc trên cung hàm

+ Trẻ đang điều trị chỉnh nha bằng mắc cài cố định.

+ Trẻ đang hoặc mới ngừng điều trị sâu răng bằng các biện pháp fluor tại chố $<6$ tháng.

+ Trẻ có tiền sử dị ứng với fluor

+Trẻ đang điều trị bằng các thuốc có phản ứng chéo với fluor như: cholohexatidine...

+ Trẻ đang có bệnh toàn thân.

+ Trẻ không hợp tác.

\subsection{Phương pháp nghiên cứu}

* Thiết kế nghiên cứu: Là một nghiên cứu can thiệp lâm sàng ngẫu nhiên có nhóm chứng, mù đôi nhằm đánh giá hiệu quả phòng và điều trị sâu răng vĩnh viễn của véc-nifluor, sau 6 tháng, 12 tháng và 24 tháng theo dõi.

*Mẫu nghiên cứu. Chúng tôi dựa theo công thức tính cỡ mẫu cho nghiên cứu can thiệp của Lwanga [17].

$$
\mathrm{n}=\frac{\left\{z_{1-\alpha / 2} \sqrt{2 \overline{\mathrm{P}}(1-\overline{\mathrm{P}})}+z_{1-\beta} \sqrt{\mathrm{P}_{1}\left(1-\mathrm{P}_{1}\right)+\mathrm{P}_{2}\left(1-\mathrm{P}_{2}\right)}\right\}^{2}}{\left(\mathrm{P}_{1}-\mathrm{P}_{2}\right)^{2}}
$$

$Z_{(1-0 / 2)}$ : hệ số tin cậy ở mức xác suất $95 \%$ $(=1,96) ; Z_{1-0}$ : lực mẫu $(=90 \%)$

$P_{1}$ : tỷ lệ sâu răng vĩnh viển trong nhóm can thiệp, sau 24 tháng theo dõi ước lượng là $25 \%$

$\mathrm{P}_{2}$ : tỷ lệ sâu răng vĩnh viến trong nhóm chứng, ước lượng là $45 \%$ sau 24 tháng theo dõi

$\mathrm{P}:\left(\mathrm{P}_{1}+\mathrm{P}_{2}\right) / 2$

$\mathrm{n}_{1}$ : cỡ mẫu nhóm can thiệp (số học sinh được chải véc-ni fluor)

n2: cõ mẫu nhóm đối chứng (số học sinh được chải kem Colgate trẻ em) 
Sự khác biệt có ý nghĩa lâm sàng tối thiểu: $\delta$ $=10 \%(0,10)$, nghĩa là chênh lệch mong muốn giữa nhóm thử nghiệm và nhóm chứng $\geq 10 \%$ với xác suất $5 \%$, do đó $\beta=-1,645$.
Theo công thức tính được cỡ mẫu cần thiết tối thiểu cho 2 nhóm nghiên cứu là $n=n_{2}=n_{1}=108$ học sinh (làm tròn $120 \mathrm{HS}$ ) tổng số học sinh cho 2 nhóm trong nghiên cứu can thiệp là 240 em.

Thiết kếnghiên cứu được minh họa qua sơ đồ sau:

Khám răng miệng, Đánh giá tình trạng răng theo ICDAS

Thời điểm ban đầu T0

Mẫu nghiên cứu ( 258 bênh nhân)

+ Lên danh sách các học sinh có ít nhất 1 răng sâu vĩnh viễn

+ Lựa chọn ngẫu nhiên các học sinh đồng ý tham gia vào nghiên cứu can thiệp

Phân chia ngẫu nhiên

Nhóm 1: Nhóm can thiệp

Dùng kem+ kết hợp với bôi Vecni Flour (6 tháng/ lần)

Nhóm 2: Nhóm chứng Chỉ dùng kem

\section{Thời điểm sau 6 tháng (T1), 12 tháng (T2), và sau 24 thána $(\mathrm{T} 3)$ \\ Khám rănq miêng, đánh giá lại tình trạng rănq theo ICDAS \\ So sánh các giá trị đánh giá tình trạng giữa 2 nhóm theo các thời điểm}

\section{Sơ đồ thiêt kếnghiên cứu can thiệp lâm sàng ngẫu nhiên có đôî chứng}

*Chọn mẫu: Từ danh sách học sinh được chọn, chúng tôi sử dụng máy tính phân bổ ngẩu nhiên vào hai nhóm (theo phầm mềm $\mathrm{R}$ ):

+ Nhóm can thiệp $\left(\mathbf{n}_{\mathbf{1}}\right): \mathbf{1 2 0}$ học sinh sử dụng răng với véc-ni fluor 6 tháng/lần.

+ Nhóm chứng $\left(\mathbf{n}_{2}\right): 120$ học sinh chỉ được chải răng với kem chải răng Colgate trẻ em (500 ppm fluor).

Theo công thức tính được cỡ mẫu cần thiết tối thiểu cho 2 nhóm nghiên cứu là $n 1=n 2=$ 108 học sinh. Để đề phòng mất đối tượng nghiên cứu do thời gian theo dõi dài, chúng tồi lấy thêm $30 \%$. Cụ thể chúng tôi đã can thiệp trên cỡ mẫu: nhóm can thiêp $n=162$, nhóm đối chứng $n=155$. Qua theo dõi 4 đợt khám trong 24 tháng, cõ mẫu nghiên cứu chúng tôi thu được:

-Ớ nhóm can thiệp:

+ Khám lân 1: 162 học sinh tương đương 100\%

+ Khám lân 2: 156 học sinh tương đương 96,29\%

+ Khám lân 3: 141 học sinh tương đương 87,03\%
+ Khám lân 4: 130 học sinh tương đương 80,24\% $\Rightarrow$ Mất 32 đối tượng nghiên cứu, tương đương 19,75\% so với ban đầu

-ở nhóm đối chứng:

+ Khám lần 1: 155 học sinh tương đương 100\%

+ Khám lần 2: 148 học sinh tương đương 95,48\%

+ Khám lần 3: 133 học sinh tương đương 85,80\%

+ Khám lân 4: 128 học sinh tương đương 82,58\%

$\Rightarrow$ Mất 27 đối tượng nghiên cứu, tương đương $17,42 \%$ so với ban đầu

Tuy nhiên, so với cõ̃ mẫu đã tính theo công thức, sau can thiêp cả nhóm can thiệp $(n=130)$ và nhóm đối chứng $(n=128)$ để có cõ̃ mẫu lớn hơn cỡ mẫu tối thiểu cần có $(n=108)$. Vì vậy cõ mẫu trong nghiên cứu đảm bảo tính khoa học.

2.4. Tiêu chuẩn sử dụng trong đánh giá tổn thương sâu răng. Chúng tôi sử dụng tiêu chuẩn đánh giá và ghi nhân sâu răng của hê thống đánh giá và phát hiện sâu răng quốc tể ICDAS [6] trên lâm sàng.

\section{KẾT QUẢ NGHIÊN CỨU}

\subsection{Thông tin chung về đối tượng nghiên cứu}

Bảng 3.1. Phân bố tỷ lệ hoc sinh trong nghiên cứu can thiệp

\begin{tabular}{|c|c|c|c|c|c|c|c|}
\hline \multirow{2}{*}{$\begin{array}{l}\text { Nhóm } \\
\text { Giới tính }\end{array}$} & \multicolumn{2}{|c|}{ Can thiệp } & \multicolumn{2}{|c|}{ Chứng } & \multicolumn{2}{|c|}{ Tống } & \multirow{2}{*}{$\mathbf{p}$} \\
\hline & Số lượng & Tỷ lệ \% & Số lượng & Tỷ lệ \% & Số lượng & Tỷ lệ \% & \\
\hline Nam & 69 & 50,0 & 69 & 50,0 & 138 & 53,5 & $>0,05$ \\
\hline
\end{tabular}




\begin{tabular}{|c|c|c|c|c|c|c|c|}
\hline Nữ & 59 & 49,2 & 61 & 50,8 & 120 & 46,5 & \\
\hline Tống & 128 & 49,6 & 130 & 50,4 & 258 & 100,0 & \\
\hline \multicolumn{8}{|c|}{$\begin{array}{l}\text { Nhận xét: Tỷ lệ học sinh nam chung là } 53,5 \% \text {, tỷ lệ học sinh nữ là } 46,5 \% \text {, không có khác biệt } \\
\text { tỷ lệ giới tính nam và giới tính nữ ở các nhóm can thiệp và nhóm chứng. } \\
\text { Bảng 3.2. Phân bố tỷ lệ học sinh theo dịa dư trong nghiên cứu can thiẹp }\end{array}$} \\
\hline Nhóm & \multicolumn{2}{|c|}{ Can thiệp } & \multicolumn{2}{|c|}{ Chứng } & \multicolumn{2}{|c|}{ Tống } & \multirow[b]{2}{*}{ p } \\
\hline Địa dư & Số lượng & Tỷ lệ \% & Số lượng & Tỷ lệ \% & Số lượng & Tỷ lệ \% & \\
\hline Quận & 64 & 49,2 & 66 & 50,8 & 130 & 50,4 & \multirow{3}{*}{$>0,05$} \\
\hline Thị xã/Huyện & 64 & 50,0 & 64 & 50,0 & 128 & 59,6 & \\
\hline Tống & 128 & 49,6 & 130 & 50,4 & 258 & 100,0 & \\
\hline
\end{tabular}

Nhận xét: Số học sinh ở Quận và Huyện tương đương nhau, chiếm $50 \%$.

3.2. Hiệu quả của véc-ni fluor trên tổn thương sâu răng vĩnh viễn qua sự thay đổi tỷ lệ sâu răng

Bảng 3.3. Tỷ lệ sâu răng vĩnh viễn số 6 bao gôm tất cả các tôn thương sâu răng (D1, D2, D3) ở nhóm can thiệp và nhóm chứng theo thời gian ( $=258)$

\begin{tabular}{|c|c|c|c|c|c|c|}
\hline \multirow{2}{*}{ Thời gian } & \multirow{2}{*}{ Nhóm } & \multicolumn{2}{|c|}{ Sâu răng } & \multicolumn{2}{|c|}{ Không sâu } & \multirow[b]{2}{*}{$\mathbf{p}$} \\
\hline & & Số lượng & Tỷ lệ \% & Số lượng & Tỷ lệ \% & \\
\hline \multirow{2}{*}{$\begin{array}{c}\text { Trước can } \\
\text { thiệp }\end{array}$} & Can thiệp & 85 & 66,4 & 43 & 33,6 & \multirow{2}{*}{$>0,05$} \\
\hline & Chứng & 73 & 56,2 & 57 & 43,8 & \\
\hline \multirow{2}{*}{ Sau 06 tháng } & Can thiệp & 75 & 58,6 & 53 & 41,4 & \multirow{2}{*}{$>0,05$} \\
\hline & Chứng & 79 & 60,8 & 51 & 39,2 & \\
\hline \multirow{2}{*}{ Sau 12 tháng } & Can thiệp & 67 & 52,3 & 61 & 47,7 & \multirow{2}{*}{$<0,05$} \\
\hline & Chứng & 88 & 67,7 & 42 & 32,3 & \\
\hline \multirow{2}{*}{ Sau 24 tháng } & Can thiệp & 52 & 40,6 & 76 & 59,4 & \multirow{2}{*}{$<0,001$} \\
\hline & Chứng & 102 & 78,5 & 28 & 21,5 & \\
\hline
\end{tabular}

Nhân xét: Tỷ lê sâu răng bao gồm tất cả các tống thương sâu răng (D1,D2,D3) ở nhóm can thiêp có xu hướng giảm theo thời gian từ $66,4 \%$ tại thời điểm T0 và giảm xuống 40,6\% tại thời điểm T3 sau 24 tháng. Ở nhóm chứng có xu hướng tăng lên từ 56.2\% tại thời điểm T0, tăng lền sau 6 tháng T1 là $56.2 \%$, sau 24 tháng T3 là $78.5 \%$.

Bảng 3.4. Mối liên quan giữa tỷ lệ sâu răng vĩnh viễn số 6 bao gôm các tổn thương sâu răng (D1, D2, D3) với đlia dư của nhóm can thiệp theo thời gian

\begin{tabular}{|c|c|c|c|c|c|c|c|}
\hline \multirow{3}{*}{ Thời gian } & \multirow{3}{*}{ Địa dư } & \multicolumn{4}{|c|}{ Can thiêp ( $n=128$ học sinh) } & \multirow{3}{*}{ Tổng } & \multirow{3}{*}{$\mathbf{p}$} \\
\hline & & \multicolumn{2}{|c|}{ Sâu } & \multicolumn{2}{|c|}{ Không } & & \\
\hline & & Số lượng & Tỷ lệ & Số lượng & Tỷ lệ & & \\
\hline \multirow{2}{*}{ Trước CT } & Quận & 39 & 60,9 & 25 & 39,1 & 64 & \multirow{2}{*}{$>0,05$} \\
\hline & Huyện & 46 & 71,9 & 18 & 28,1 & 64 & \\
\hline \multirow{2}{*}{6 tháng } & Quận & 33 & 51,6 & 31 & 48,4 & 64 & \multirow{2}{*}{$>0,05$} \\
\hline & Huyện & 42 & 65,6 & 22 & 34,4 & 64 & \\
\hline \multirow{2}{*}{12 tháng } & Quận & 29 & 45,3 & 35 & 54,7 & 64 & \multirow{2}{*}{$>0,05$} \\
\hline & Huyện & 38 & 59,4 & 26 & 40,6 & 64 & \\
\hline \multirow{2}{*}{24 tháng } & Quận & 20 & 31,3 & 44 & 68,8 & 64 & \multirow{2}{*}{$>0,05$} \\
\hline & Huyện & 31 & 48,4 & 33 & 51,6 & 64 & \\
\hline
\end{tabular}

Nhận xét: Tại nhóm can thiệp với 128 học sinh sau 24 tháng sử dụng bôi véc-ni fluor thì tỷ lệ sâu răng (D̂̉, D2, D3) đều giảm. Và sự giảm này với $p>0.05$ chứng tỏ hiệu quả can thiệp bằng véc-ni fluor đều có tác dụng giảm chung không ảnh hưởng bởi yếu tố địa dư.

Bảng 3.5. Mồi liên quan giữa tỷ lệ sâu răng vĩnh viễn số 6 bao gôm các tổn thương sâu răng (D1, D2, D3) với đỉa dư của nhóm không can thiệp theo thời gian

\begin{tabular}{|c|c|c|c|c|c|c|c|}
\hline \multirow{3}{*}{ Thời gian } & \multirow{3}{*}{ Địa dư } & \multicolumn{4}{|c|}{ Không can thiệp $(n=130)$} & \multirow{3}{*}{ Tổng } & \multirow{3}{*}{$\mathbf{p}$} \\
\hline & & \multicolumn{2}{|c|}{ Sâu } & \multicolumn{2}{|c|}{ Không } & & \\
\hline & & Số lượng & Tỷ lệ & Số lượng & Tỷ lệ & & \\
\hline \multirow{2}{*}{ Trước CT } & Quận & 34 & 51,5 & 32 & 48,5 & 66 & \multirow{2}{*}{$>0,05$} \\
\hline & Huyện & 39 & 60,9 & 25 & 39,1 & 64 & \\
\hline \multirow{2}{*}{6 tháng } & Quận & 36 & 54,5 & 30 & 45,5 & 66 & \multirow{2}{*}{$>0,05$} \\
\hline & Huyện & 43 & 67,2 & 21 & 32,8 & 64 & \\
\hline
\end{tabular}


VIETNAM MEDICAL JOURNAL N01 - AUGUST - 2021

\begin{tabular}{|c|c|c|c|c|c|c|c|}
\multirow{2}{*}{12 tháng } & Quận & 43 & 65,2 & 23 & 34,8 & 66 & $>0,05$ \\
\cline { 2 - 8 } & Huyện & 45 & 70,3 & 19 & 29,7 & 64 & \\
\hline \multirow{2}{*}{24 tháng } & Quận & 49 & 74,2 & 17 & 25,8 & 66 & $>0,05$ \\
\cline { 2 - 8 } & Huyện & 53 & 82,8 & 11 & 17,2 & 64 & $>0$ \\
\end{tabular}

Nhân xét: Tai nhóm không can thiêp với 130 học sinh sau 24 tháng sử dụng bôi véc-ni fluor thì tỷ lệ sẩu răng (D1, D2, D3) đều tăng.

\section{BÀN LUẬN}

4.1. Một số thông tin chung của nhóm can thiệp và nhóm đối chứng. Nghiên cứu này được tiến hành sau một nghiên cứu mô tả cắt ngang tại thành phố Hà Nội. Từ kết quả sơ bộ của nghiên cứu cắt ngang, chúng tôi chọn ngẫu nhiên 1 Quân và 1 Huyện đại diện cho 6 Quận, Huyện nghiên cứu. Sau đó phân chia ngẫu nhiên ở Quận và Huyện làm 2 nhóm can thiệp và nhóm chứng. Kết quả phân tích ở Bảng 3.1 cho thấy, trong cả nhóm chứng và nhóm can thiệp, tỷ lệ học sinh nữ gần tương đương tỷ lệ học sinh nam giới. Không có sự khác biệt có ý nghĩa thống kê giữa hai nhóm can thiệp và nhóm chứng, và số lượng học sinh giữa Quận và Huyện (Bảng 3.2), đảm bảo được tính đồng nhất sẽ giúp cho việc so sánh và phân tích số liệu có độ tin cậy cao, hạn chế yếu tố nhiễu, đồng thời giảm được sai số hệ thống.

4.2. Hiệu quả dự phòng sâu răng của véc-ni fluor $\mathbf{5 \%}$. Trước can thiệp, tỷ lệ sâu răng ở nhóm chứng là $56,2 \%$ tăng lên $60,8 \%$ sau can thiệp 6 tháng, 67,7\% sau can thiệp 12 tháng và $78,5 \%$ sau can thiệp 24 tháng. Ở nhóm can thiệp, tỳ lệ sâu răng ban đầu là $66,4 \%$, tỷ lệ này giảm còn $58,6 \%$ sau can thiệp 6 tháng, $52,3 \%$ sau can thiêp 12 tháng và $40,6 \%$ sau can thiệp 24 tháng (Bảng 3.3). Kết quả nghiên cứu cho thấy thời gian can thiệp càng dài thì tỷ lệ sâu răng càng giảm đã cho thấy hiệu quả rõ rệt của véc-ni fluor $5 \%$ trên tổn thương sâu răng, tuy nhiên nghiên cứu chưa chứng minh được phải can thiệp kéo dài trong bao lâu thì tỷ lệ sẩu răng triệt tiêu hoàn toàn. Điều này có thể sẽ không xảy ra vì nhiêu nghiên cứu tác dụng của fluor đã chứng minh rằng, fluor chỉ có thể hoàn nguyên được các tổn thương sâu răng sớm (tương ứng với ICDAS mã số 1 và 2 [9], còn khi sâu răng đã hình thành lỗ, fluor chỉ có tác dụng làm chậm sự phát triển của tổn thương sâu [5],[7]. Như vậy, tỷ lệ sâu răng của nhóm can thiệp trong nghiên cứu giảm là do véc-ni fluor đã có tác dụng làm hoàn nguyên các tổn thương sâu răng ở mã số ICDAS 1 và 2 như các nghiên cứu trước đây đã chứng minh.

Để đánh giá hiệu quả dự phòng sâu răng của véc-ni fluor so với kem chải răng, chúng tôi bắt đầu phân tích kết quả can thiêp ở thời điểm sau 6 tháng giữa hai nhóm. Kết quả bảng 3.3 cho thây, tỷ lệ sâu răng ở nhóm chứng tăng từ $56,2 \%$ lên $60,8 \%$, còn ở nhóm can thiệp, tỷ lệ sâu răng giảm từ $66,4 \%$ xuống còn $58,6 \%$. Như' vậy, sau 6 tháng bôi véc-ni fluor $5 \%$ cho thấy nhóm can thiệp đã có sự giảm tỷ lệ bệnh. Sau 12 tháng và 24 tháng can thiệp, tỷ lệ sẩu răng ở nhóm chứng tăng và nhóm can thiêp tiếp tuc giảm.

Như vậy, véc-ni fluor $5 \%$ có hiệu quả bảo vệ răng không bị sâu hơn so với kem đánh răng. Kết quả này cũng phù hợp với kết quả nghiên cứu của một số tác giả nước ngoài. Nghiên cứu hệ thống của Valeria CC Marinho et al VC và cộng sự 2002, với 12455 người tham gia ngẫu nhiên (trong đó 9595 được sử dụng phân tích), chỉ số $D(M) F S$ giảm 43\% (khoảng tin cậy $95 \%$ (Cl) $30 \%-57 \% ; p \leq 0,0001)$ [1]. Kết quả nghiên cứu của chúng tôi có hiệu quả hơn kết quả nghiên cứu của Vũ Mạnh Tuấn [8] và Trần Thị Kim Thúy [9], điều này được giải thích do chúng tôi sử dụng dạng véc-ni fluor có làm lượng ion $\mathrm{NaF} 5 \%$ cao hơn 2 nghiên cứu kia chỉ sử dụng dạng gel fluor $1,23 \%$.

\section{KẾT LUẬN}

Véc-ni fluor 1,23\% có hiệu quả dự phòng bệnh sâu răng trẻ em cao hớn so với kem chải răng có fluor, thể hiện ở: tỷ lệ giảm các tỷ lệ sâu răng ở nhóm can thiệp.

\section{TÀI LIỆU THAM KHẢO}

1. Valeria CC Marinho et al (2013). Fluoride varnishes for preventing dental caries in children and adolescents. Cochrane Database of Systematic, Issue 7.

2. Debbie Bonetti, Jan E. Clarkson (2016). Fluoride Varnish for Caries Prevention: Efficacy and Implementation. Caries Research, 50 (suppl 1): 45-49.

3. Robert J. Weyant et al (2013). Topical fluoride for caries prevention. ADA Center for EvidenceBased Dentistry.

4. Marinho VCC, Higgins JPT, Logan S, Sheiham A (2009). Flourish varnish for preventing detal caries in children and adolescents 2009.

5. Kuldeep Dhama et al (2017). Topical Fluorides. Anchor Academic Publishing.

6. Lena Karlsson (2009). Optical based technologies for detection of dentel caries. Karolinska Institutet.Marinho VC, Higgins JP, Logan $S$ et al (2003). Systematic review of controlled trials on the effectiveness of fluoride gels for the prevention of dental caries in children. J. Dent 
Educ, 67(4), 448-458

7. Trân Văn Trường, Lâm Ngọc Ấn, Trịnh Đình Hải và công sứ (2001). Điều tra sức khỏe răng miênng toàn quốc, Nhà xuất bản Y học, Hà Nội, 67-75.

8. Vữ Manh Tuấn (2013). Nghiên cứu dự phòng sâu răng bằng Gel fluor, Luận án Tiến sĩ y học,
Trường Đai hoc $Y$ Hà Nôii.

9. Trân Thị Kim Thúy (2019). Nghiên cứu dự phòng sâu răng vĩnh viến giai đoan sớm bằng nước sức miệng flour cho học sinh 7-8 tuổi ở tỉnh Phú Thọ, Luận án tiến sỹ y học, Viện nghiên cứu khoa học y dược lâm sàng 108.

\section{ĐÁNH GIÁ KẾT QUẢ THỤ TINH TRONG ỐNG NGHIÊMM TRÊN BÊNNH NHÂN ĐƯỢC TRƯởNG THÀNH NANG NOÃN BẰNG GnRH AGONIST TẠI BỆNH VIỆN PHỤ SẢN TRUNG ƯO'NG NĂM 2019}

\section{TÓM TẮT}

Trong những năm gân đây GnRH agonist là thuốc được sử dụng để gây trưởng thành nang noãn thay thể hCG trong phác đồ Antagonist, kết hợp với đông phôi toàn bô và chuyển phôi đông lannh là môt giải pháp toàn diện giảm thiểu hội chứng quá kích buồng trứng trong thu tinh trong ống nghiếm. Mục tiêu: 1) Mô tả một số đặc điểm của bệnh nhân kích thích buồng trứng bằng phác đồ GnRH antagonist được gây trưởng thành nang noãn bằng $\mathrm{GnRH}$ agonist. 2) Đánh giá kết quả thụ tinh trong ống nghiệm của những bệnh nhân trên. Đối tượng và phương pháp: Nghiên cứu thực hiện trên 90 bệnh nhân thông qua hồ sơ bệnh án kết hợp phỏng vấn qua điện thoại. Kết quả: Tất cả bệnh nhân không phải nhập viện điều trị hội chứng quá kích buồng trứng (HCQKBT), chỉ ghi nhận bị quá kích buồng trứng $(13,33 \%)$ ở mức độ nhẹ. Số lượng noãn trung bình thu được là 20,91 \pm 7,13 noãn, số noãn MII chiếm tỷ lệ 77,79\%. Tỷ lệ thụ tinh trung bình đat $79,95 \pm 20,01 \%$, số phôi trung bình thu được $13,27 \pm 6,21$ phôi. Kết quả thụ tinh trong ống nghiệm được ghi nhân tốt, với tỷ thai sinh hóa đạt $55,20 \%$, tỷ lệ thai lâm sàng đạt $44,03 \%$ và tỷ lệ thai sinh sống đạt 34,33\%. Kết luận: Thụ tinh trong ống nghiệm bằng phác đồ Antagonist và trưởng thành noãn bằng GnRha cho kết quả tốt về tỷ lệ noãn trưởng thành (MII) và tỷ lệ thụ tinh tỷ lệ thai lâm sàng và tỷ lệ thai sinh sống cao. Tỷ lệ bệnh nhân quá kích buồng trứng giảm nhiều, đặc biệt không xảy ra tình trạng quá kích buồng trứng nặng.

Tư khóa: GnRH agonist, quá kích buông trứng, thụ tinh trong ống nghiệm.

\section{SUMMARY \\ EVALUATION OF THE RESULTS OF IN VITRO FERTILIZATION IN PATIENTS MATURED FOLLICLE BY USING GNRH AGONIST AT THE NATIONAL HOSPITAL OF OBSTRETICS AND GYNECOLOGY IN 2019}

${ }^{1}$ Bệnh viện đa khoa Hà Nội

${ }^{2}$ Bệnh viện phụ sản Trung Uơng

Chịu trách nhiệm chính: Nguyễn Duy Phương

Email: drnguyenduyphuong@gmail.com

Ngày nhận bài: 17.5.2021

Ngày phản biên khoa hoc: 5.7.2021

Ngày duyệt bài: 19.7.2021

\section{Nguyễn Duy Phương ${ }^{1}$, Nguyễn Xuân Họoi ${ }^{2}$}

In recent years, GnRH agonist is know as the drug used to trigger follicular maturation instead of hCG in Antagonist regimen, combined with whole embryo freezing and frozen embryo transfer (FET) is a comprehensive solution to minimize ovarian hyperstimulation syndrome (OHSS) in in vitro fertilization. Objectives: 1) Describe some features of patients stimulate ovarian with $\mathrm{GnRH}$ antagonist regimen who were triggered for follicular maturation by $\mathrm{GnRH}$ agonist. 2) Evaluate the results of in vitro fertilization of these patients. Subjects and methods: The study was carried out by descriptive retrospective method, on 90 patients based on the combination of medical records and phone interviews. Results: For all patients did not need to hospitalize for ovarian hyperstimulation syndrome (OHSS), only ovarian hyperstimulation at mild level $(13.33 \%)$ was recorded. The average number of oocytes obtained was $20.91 \pm 7.13$ oocytes, the number of matured oocytes accounted for $77.79 \%$. Additionally, the average fertilization rate was $79.95 \pm 20.01 \%$ and the average number of embryos was $13.27 \pm 6.21$ embryos. The results of in vitro fertilization were well recorded, with the biochemical pregnancy rate reaching $55.20 \%$, the clinical pregnancy rate reaching $44.03 \%$, and the live birth rate reaching $34.33 \%$. Conclusion: In vitro fertilization with an Antagonist regimen and oocyte maturation by GnRha gave good results in oocyte maturation rate, fertilization rate, clinical pregnancy rate, and live birth rate. The proportion of patients with ovarian hyperstimulation decreased significantly, especially there was no severe ovarian hyperstimulation. Keywords: GnRH agonist, ovarian hyperstimulation, in vitro fertilization.

\section{I. ĐẶT VẤN ĐỀ}

Kích thích buồng trứng trong thụ tinh ống nghiệm (TTTON) bằng phác đồ antagonist đang là lựa chọn ưu tiên số một hiện nay bởi những ưu việt vượt trội so với các phác đồ khác như thời gian kích thích buồng trứng ngắn, lượng thuốc sửa dụng ít hơn so với các phác đồ khác giúp tiết kiệm chi phí, không hình thành nang chức năng, giống với sinh lý hơn,... Trước đây hCG là thuốc mặc định dùng để gây trưởng thành nang noãn trong phác đồ trên, tuy nhiên 